\title{
“NOTÍCIAS” DO THE Í-PIAUÍ HERALD E CONTEXTO: \\ UM ESTUDO SOB \\ O VIÉS SOCIOCOGNITIVISTA \\ DA LINGUAGEM
}

\section{"NOTICIAS" DE LA Í- PIAUÍ HERALD Y CONTEXTO: UN ESTUDIO SOSLAYADO DEL SOCIOCOGNITIVISTO EN EL IDIOMA}

THE I-PIAUI HERALD'S "NEWS" AND CONTEXT: A STUDY UNDER THE SOCIO-COGNITIVE BIAS OF LANGUAGE

Nadiana Lima da Silva* Universidade Federal de Pernambuco

RESUMO: O objetivo do presente estudo é observar de que maneira funcionam as pistas contextuais de notícias fictícias do blog The i-Piauí Herald (subordinado à Revista Piauí), observando o que as aproxima e as distancia das notícias "reais", bem como as pistas que as aproximam de outro gênero, a charge. Para tanto, analiso quatro notícias fictícias publicadas entre 09/10/13 e 11/11/13, por se relacionarem a um mesmo momento discursivo escolhido e por serem subsequentes com pequena diferença temporal entre si. Guio-me, para esse fim, pela perspectiva sociocognitivista da linguagem, mais especificamente no que diz respeito à noção de contexto (VAN DIJK, 2012) e ao processo de referenciação (MONDADA; DUBOIS, 2003).

PALAVRAS-CHAVE: notícias fictícias; contexto; sociocognitivismo; gêneros.

*Doutoranda em Letras/Linguística. E-mail para contato: nadianalima@gmail.com 
RESUMEN: El objetivo de este estudio es observar cómo funcionan las pistas contextuales de noticias ficticias del blog The i-Piauí Herald (subordinado a la Revista Piauí), observando lo que las aproxima y las distancia de las noticias reales, así como las pistas que las aproximan de otro género, la viñeta. Para eso, analizo cuatro noticias ficticias publicadas entre 09/10/13 y 11/11/13, por relacionarse a un mismo tiempo al discursivo escogido y porque son subsecuentes con pequeña diferencia temporal entre sí. Me guío, para este fin, por la perspectiva sociocognitivista del lenguaje, más específicamente la que se ha centrado en la noción de contexto (VAN DIJK, 2012) y en el proceso de referencias (MONDADA; DUBOIS, 2003).

PALABRAS CLAVE: noticias fictícias; contexto; sociocognitivismo; géneros.

ABSTRACT: The aim of this study is to observe how the contextual clues from the fictitious news published in The I-Piaui Herald work (from the Piaui magazine), observing what bring the closer or push them further from the real news, as well as the clues that approximate them of another genre - charge. To do so, we have analyzed four fictitious pieces published between October 9,2013 and November 11,2013, for being related to the same discursive moment, and for being subsequent, with little temporal distance among them. We were guided by the socio-cognitive perspective of language, more specifically the notion of context (VAN DIJK, 2012), and the referencing process (MONDADA; DUBOIS, 2003).

KEYWORDS: fictitious news; context; socio-cognitivism; genres.

\section{INTRODUÇÃO ${ }^{1}$}

Subvertendo parcialmente o que se espera de uma introdução, começo pela discussão do título deste estudo. Assim como em notícias, sobretudo quando ocorrem em suas manchetes, as aspas conferem destaque a um termo ou uma expressão que, por ativação de conhecimento prévio, se refere a uma voz reportada, a um discurso outro, o que culmina em uma distância da voz do jornalista. No entanto, as aspas têm recorrente papel de desestabilizar o valor do que está entre elas, muitas vezes em indicativo de dúvida, de ironia ou de questionamento. Aqui, revelam não só o esvaziamento de uma tipologia inadequada, uma vez que tratarei de outro gênero que não é notícia, mas também a indecisão de como chamá-lo. Passa a ser, então, também um convite à reflexão sobre esse tópico que ultrapassa os objetivos e o espaço deste trabalho.

Entretanto, a referência ao gênero notícia não é despropositada: trata-se da ativação de conhecimento metagenérico, que é mobilizado ao se ler os textos que compõem o corpus, que, por ora, direi que são exemplares de notícias fictícias (doravante NF). Estas apresentam um forte teor humorístico e - como orienta este nome que estou cunhando provisoriamente - são falsas, fabricadas com fins (ao menos, superficialmente) de entretenimento. Embora fictícias, são construídas com base em notícias “reais”, sua compreensão é tributária, em boa parte, do conhecimento dos 'fatos' noticiados pela mídia, bem como seus desmembramentos. Assim, não me parece ser um caso de intergenericidade, em que há uma utilização de um gênero no formato de outro, mas da confluência de traços composicionais não só do gênero notícia como também do gênero charge, uma aproximação arriscada que realizo em função de uma hipótese que permeia estes escritos: algumas estratégias textual-discursivas, especificamente as que dizem respeito à ativação de conhecimento prévio (ou pistas contextuais por meio do que van Dijk chamou de mecanismo-k, sobre o qual discorremos adiante), funcionam em NFs de maneira semelhante às que ocorrem em charges; por outro lado, distanciam-se sobremaneira das notícias também por este ponto.

Novamente por questões de espaço, irei me abster de recorrer à reprodução de notícias ou de charges para efeitos de comparação; discorrerei em pressuposto sobre o compartilhamento de conhecimento acerca do funcionamento desses gêneros.

\footnotetext{
${ }^{1}$ Trabalho resultante da disciplina Tópicos Avançados em Linguística de Texto, oferecido pelo PPGL-UFPE e ministrado pela prof ${ }^{\mathrm{a}}$ Dra ${ }^{\mathrm{a}}$ Karina Falcone, no segundo semestre de 2013, a quem agradeço pelos inestimáveis ensinamentos e pelo incentivo à publicação em revista.
} 
Diante dessa hipótese, procurei estudar o funcionamento de NFs, coletadas do blog The i-Piauí Herald, entre os dias 09/10/13 e $11 / 11 / 13$, por estarem relacionadas ao momento discursivo ${ }^{2}$ referente à polêmica das biografias não autorizadas, celeuma que envolveu grandes nomes da MPB em confronto com autores de biografias, cuja publicação não passou pelo crivo de seus respectivos biografados, o que gerou intensa produção midiática, polarizando a opinião pública entre os defensores da liberdade de expressão e da manutenção da privacidade. Além disso, as NFs escolhidas apresentam pequena diferença temporal entre si, o que permite uma boa visibilidade de como se processa a referência a fatos passados dentro do âmbito da publicação do blog.

\section{TEXTO, GÊNERO, CONTEXTO, DISCURSO: QUANDO A SOCIOCOGNIÇÃO É O FIO DAS MIÇANGAS}

Mais uma vez, começo um tópico recorrendo a uma metalinguagem. Não há como, depois de um título ambicioso como este, não lançar mão de uma proteção de face: como toda ambição desmedida está fadada ao fracasso se não houver ponderação quanto ao que se almeja, deixo claro que meu propósito, nesta seção assim intitulada, é frisar a impossibilidade de tratar de uma dessas noções sem que se leve em conta as demais, mesmo que todas elas não sejam devidamente tratadas com profundidade. Em nossos modelos mentais acerca dos eventos - que estão sendo ativados, agora mesmo, no momento de escrita deste texto (para mim) e na leitura dele (para quem o lê) -, na posição de pesquisadores na área da linguagem, sabemos que estas noções permeiam a compreensão da comunicação humana e são decisivos para a análise de qualquer texto.

Ao pensar sobre o funcionamento de NFs, estive não só diante de uma indefinição quanto ao gênero, mas também de questões, tais quais: como opera sua textualidade? Quais modelos de contextos estão envolvidos em sua compreensão? Que discursos são construídos nesse processo? Portanto, mais disposta a refletir sobre essas questões preliminarmente do que propriamente responder a essas questões, inicio definindo o fio que norteará essa empreitada: o sociocognitivismo.

Vencendo a visão descorporificada ${ }^{3}$ (ou desencorpada, do inglês disembodied) da relação linguagem e cognição - ou seja, da polarização entre mente e corpo, distinção rígida entre o externo e o interno -, assim como a ênfase dos estudos linguísticos ora nos aspectos mentais, sem levar em contar os aspectos sociais para fins analíticos, ora nos aspectos sociais, desconsiderando-se o papel dos processos cognitivos na investigação, a linguagem é vista como uma ação conjunta entre esses dois aspectos, uma vez que a maneira como nos relacionamos com o mundo "[...] é de uma ordem essencialmente cognitiva e interativamente semiotizada: uma ordem histórica e sócio-interativa” (MARCUSCHI, 2007, p. 125). Assim, noções como verdade, resultante da correspondência entre o mundo e o que dizemos sobre ele, e representação, como um espelhamento da 'realidade', caem por terra e precisam ser repensadas, pois não se trata de uma relação objetivizada, em que percebemos as coisas dadas naturalmente e utilizamos a língua para representá-las, mas o resultado de um agir intersubjetivo no mundo, o que sinaliza para a maneira como o percebemos, como o dizemos - o que não é uma questão de identificação de coisas reais estabelecidas a priori.

Chegamos, assim, à primeira miçanga a ser trançada por este fio: o texto. Levando em conta essa perspectiva sociocognitivista e a ideia de que não há uma realidade pré-estabelecida, apenas representada pela língua, corrobora-se a noção de texto estabelecida por Beaugrande (1997 apud MARCUSCHI, 2008, p.80), segundo a qual o texto é "[...] um evento comunicativo, no qual convergem ações linguísticas, cognitivas e sociais”. Isso quer dizer que o texto ocorre em decorrência de "[...] um complexo universo de ações humanas interativas e colaborativas", cabendo à Linguística Textual a adoção do pressuposto de que o processamento textual ocorre online " “...] simultaneamente em todos os níveis, isto é, de modo processual e holístico" (CAVALCANTE et al, 2010, p.229). Essa compreensão nos leva às implicações de que o texto é: a) um sistema de conexões de vários elementos, como som, palavra, contexto etc., em que cada um desses elementos apresenta uma função; b) multimodal, já que é construído em uma orientação de multissistemas; e c) um evento interativo, processual e coautoral (MARCUSCHI, 2008).

Em particular atenção a esta última característica dos textos, já é possível inserir a próxima miçanga: gênero. Segundo Miller (2009, p. 30), “[...] antes de podermos agir, precisamos interpretar o ambiente material indeterminado; definimos, ou 'determinamos', uma

\footnotetext{
${ }^{2}$ Termo que designa o surgimento nas mídias de uma produção discursiva intensa e diversificada a respeito de um mesmo fato (MOIRAND, 2004).

${ }^{3}$ Manteremos essa tradução ao longo deste texto.
} 
situação", tendo em vista que a ação humana é guiada pelo significado e, para chegar a possíveis interpretações, utilizamos nossos conhecimentos pré-construídos acerca de uma dada situação e os relacionamos às novas experiências, por analogia, por comparação, criando tipos de situações recorrentes. Assim, agimos de acordo com a interpretação dessas situações recorrentes tipificadas, atendendo às suas demandas. Ao mesmo tempo, atuamos de acordo com propósitos particulares diversos, o que configura tais ações como ações sociais retóricas. Para Miller, então, os gêneros são essas “ações retóricas recorrentes”, em vez de um padrão de formas prontas para realizarmos nossos próprios fins.

Bazerman (2009), em sintonia com as posições assumidas por Miller, afirma que todos os textos bem sucedidos criam, em seus leitores, "fatos sociais", que "[...] consistem em ações sociais significativas realizadas pela linguagem, ou atos de fala" (BAZERMAN, 2009, p. 22). Esses atos, por sua vez, segundo o autor, realizam-se por meio de formas textuais típicas, reconhecíveis - os gêneros que se relacionam com outros gêneros, em circunstâncias relacionadas. Partindo desse pressuposto, Bazerman (2009, p.31) explica que, ao criarmos essas formas textuais típicas, também tipificamos as situações nas quais nos encontramos e agimos em consonância com o reconhecimento dessas situações; tal processo é chamado, pelo autor, de tipificação. No entanto, o autor nos alerta que essa identificação de gêneros através de traços característicos é útil para a atribuição de sentido, mas é uma visão nebulosa, 'enganadora' do gênero. A partir dessa definição, levando em conta as formas textuais, são ignorados:

[...] o papel dos indivíduos no uso e na construção de sentidos, [...] as diferenças de percepção e compreensão, o uso criativo da comunicação para satisfazer novas necessidades percebidas em novas circunstâncias e a mudança no modo de compreender o gênero com o decorrer do tempo [...]. Os gêneros tipificam muitas coisas além da forma textual. (BAZERMAN, 2009, p.31)

Esse processo de tipificação de que se valem Miller e Bazerman para teorizar sobre os gêneros relaciona-se com a formação de modelos mentais, que são "representações cognitivas de nossas experiências". Num certo sentido, elas são as nossas experiências se assumirmos que "experiências são interpretações pessoais daquilo que acontece conosco" (VAN DIJK, 2012, p.94). Assim, diante da recorrência de uma dada experiência, passamos a tipificá-la através da formação de um modelo mental, que, por sua vez, será sempre ativado diante de situações semelhantes àquelas que motivaram sua criação.

É o momento de mais uma miçanga: contexto. Levando em conta o viés cognitivista, é proveitosa a compreensão de contexto, na esteira de van Dijk (2012), como um tipo de modelo mental, ou seja, antes mesmo de produzirmos ou lermos um texto, é preciso ativar um modelo de contexto acerca de determinado evento, que vai sempre se atualizando na medida em que interagimos. Desse modo, é preciso que compartilhemos um 'mesmo' modelo de contexto para que haja compreensão, o que exige uma pressuposição do quanto de conhecimento os interlocutores partilham entre si. Segundo van Dijk (2012), fazemos isso por meio do mecanismo$\boldsymbol{k}$, uma estratégia textual-discursiva que 'testa', 'indica', 'sinaliza', 'contextualiza' o interlocutor acerca do conhecimento que precisa ser ativado para que a interação prossiga adequadamente. No caso da esfera jornalística, em função das recorrentes notícias em torno de um dado momento discursivo, é preciso contextualizar o leitor sobre o que já foi noticiado, a fim de não só prosseguir com o assunto, mas também de evitar a repetição do que já foi dito. São frequentes inserções como "conforme noticiamos ontem...”, "saiba mais sobre o caso", "como divulgamos aqui..." (em que o dêitico "aqui" constitui um link, no caso de notícias na internet, que direciona o leitor ao texto de divulgação anterior, cuja compreensão é necessária para prosseguir a leitura do primeiro texto) etc.

Esse mecanismo é particularmente caro a este estudo na medida em que é possível vislumbrar um continnum que compreende os graus com que operam os mecanismos-k em um gênero (reconhecendo que, em certa instância, a própria estrutura genérica funciona como um mecanismo-k que nos informa sobre como proceder em sua leitura, uma vez que lemos os diferentes gêneros de maneiras distintas). Em notícias, por exemplo, como o objetivo seria informar (deixemos em suspenso a compreensão de que há diversos movimentos retóricos em uma notícia, além de elas servirem para outros propósitos), os mecanismos-k precisam ser mais explícitos e claros, a fim de que a nova informação seja apresentada "sem prejuízos" na compreensão do que se noticia. Por outro

\footnotetext{
${ }^{4}$ Para John Austin, os enunciados produzem ações, são atos de fala, por meio do qual operam três níveis/tipos de atos: o ato locucionário, que se refere ao que é dito literalmente; o ato ilocucionário, que diz respeito aos propósitos comunicativos ao se dizer determinado enunciado; e o ato perlocucionário, que consiste nas ações ou nas reações dos interlocutores a partir do que entenderam do enunciado. No entanto, essas ações realizam-se conforme as “condições de felicidade", ou seja, para que as palavras realizem atos é preciso que seja dito por uma determinada pessoa, em um determinado momento, em conformidade com compreensões compartilhadas.
} 
lado, em NFs, há muitas alusões a acontecimentos recentes que precisam ser mobilizados para que a piada/crítica se efetive, contudo as pistas contextuais por meio de mecanismos-k são bastante sutis, exigindo um maior poder inferencial. Por essa razão, aproximam-se de um gênero como a charge, cuja compreensão requisita o conhecimento prévio sobre a notícia a que se faz referência. Da mesma maneira, caso não se conheça a notícia que gerou a charge ou a NF, é possível apenas uma leitura em outro horizonte (para usar a terminologia de Marcuschi (2008) ). Veremos como isso ocorre na próxima seção.

Por fim, para fechar esse colar, é a vez da última miçanga: o discurso. Uma vez que este estudo se utiliza do aparato da Linguística Textual e se ancora em uma perspectiva sociocognitivista da linguagem, tal como foi esclarecido, parto do pressuposto, em conformidade com Mondada e Dubois (2003), que a referenciação - construção e reconstrução de objetos de discurso - constitui uma atividade discursiva e que há uma instabilidade na relação entre as coisas e as palavras. Assim, a interpretação de uma expressão anafórica, por exemplo, não consiste em identificar um segmento linguístico ou um objeto de mundo por correspondência, mas estabelecer uma relação com o conhecimento arquivado em uma memória discursiva (KOCH, 2009). No caso particular deste estudo, que visa a compreender como se dá o funcionamento do mecanismo-k em NFs, observar como opera a cadeia referencial pode ser útil para revelar os juízos de valor e posicionamentos do autor, sob o véu do humor.

\section{O FUNCIONAMENTO DO MECANISMO-K EM NFS}

O corpus de exploração é formado por oito NFs, compreendidas entre os dias 09/10/13 e 11/11/13, e giram em torno do momento discursivo referente à polêmica das biografias não autorizadas. Seus títulos são os seguintes: "Jesus exige autorização prévia para liberar Novo Testamento" (09/10/13), "Leãozinho exige autorização para ser citado por Caetano Veloso" (11/10/13), "PM carioca reprime biógrafos com truculência" (15/10/13), "Estudante da PUC-Rio é hospitalizada após discordar de artigo de Chico Buarque" (16/10/13), "Astros da MPB organizam Marcha da Família com Deus pela Privacidade (17/10/13), "Pelé desautoriza autobiografia escrita por Edson" (31/10/13), "Roberto Carlos manda Justiça recolher colunas de Caetano Veloso" (07/11/13) e "The piauí Herald lança biografias autorizadas de Paula Lavigne e Marco Feliciano” (11/11/13). Desse corpus inicial, considerei para fins analíticos apenas as primeiras 4 NFs categorizadas pelo blog como pertencentes à seção "Cultura" (reproduzidas a seguir), uma vez que há outras que relacionam notícias de outros momentos discursivos, como "PM carioca reprime biógrafos com truculência”, da seção "Brasil", que aborda a ação militar, o movimento dos Black Blocs e o lançamento da biografia de José Sarney. Inicialmente, considere-se a NF (1), "Leãozinho exige autorização para ser citado por Caetano Veloso":

\section{(1) Leãozinho exige autorização para ser citado por Caetano Veloso}

11/10/2013 17:38 | Categoria: Cultura

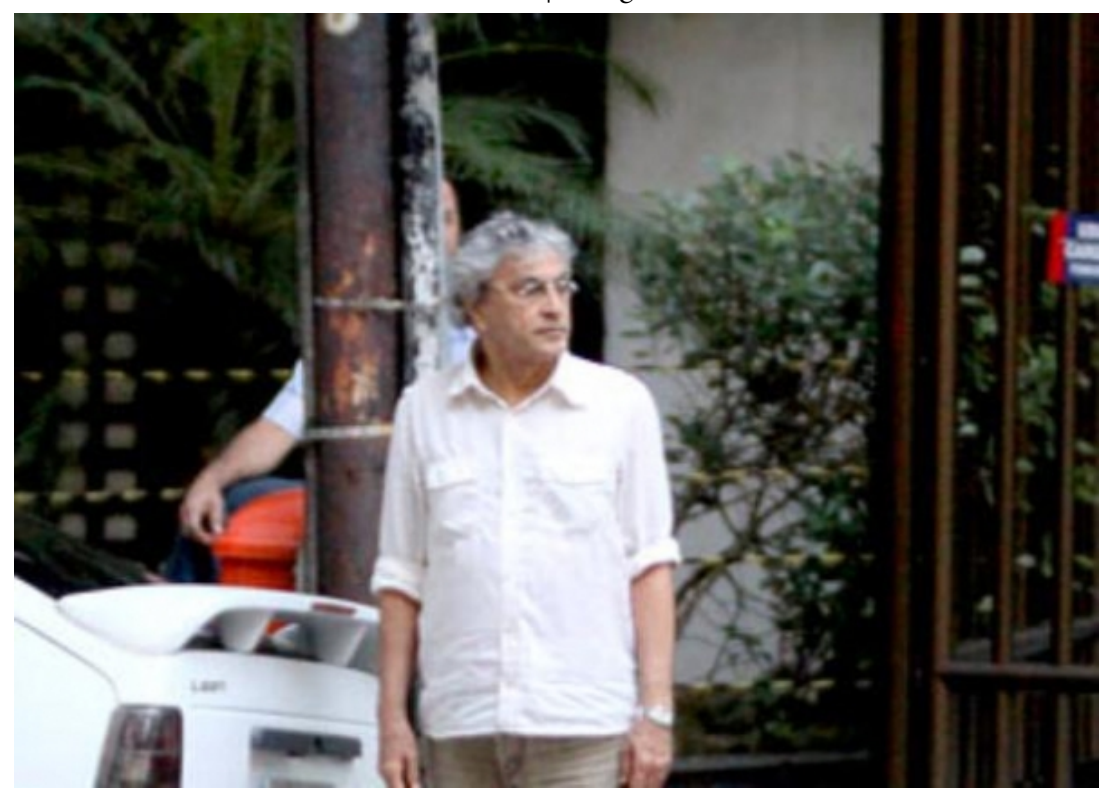

Lavigne proibiu o site Terra de revelar onde Caetano estaciona seu carro 
ODARA - Orientado por Paula Lavigne, Leãozinho proibiu Caetano Veloso de citar o seu nome. "Dados biográficos de foro íntimo foram expostos de forma vil. Agora todo mundo sabe que sou um filhote de leão raio da manhã", disse, caminhando sob o sol.

Na mesma onda, Geni resolveu processar Chico Buarque. "Foram décadas sendo apedrejada, cuspida e acusada de me relacionar com qualquer um. Nunca autorizei a citação de meu nome em músicas biográficas. Chega!", desabafou, partindo num enorme Zeppelin.

No final da tarde, Lobão fez uma sugestão a Chico Buarque. "Resolver o problema é simples: basta trocar Geni por Lavigne", tuitou.

É possível identificar um importante mecanismo-k: a composição foto-legenda, um traço estrutural padrão das NFs do corpus, a qual remete a uma publicação do portal Terra sobre o fato de Caetano Veloso ter estacionado o carro no Leblon durante um passeio, ou seja, a uma ação corriqueira do cantor que nem mesmo mereceria uma nota. Trata-se de uma fotografia "verdadeira" 5 e uma referência a uma notícia real. No entanto, o nome de Paula Lavigne, empresária do grupo Procure Saber, que agencia grandes cantores da MPB, e principal voz contra as biografias não autorizadas, é logo apresentado como símbolo de censura de uma publicação tão trivial ("Paula Lavigne proibiu o site Terra de revelar onde Caetano estaciona o carro", na legenda). Embora fabricada, essa afirmação reforça uma crítica, sob o véu do humor, às posturas consideradas autoritárias, intransigentes e, muitas vezes, antiéticas com que a empresária defende sua posição (na NF de 09/10/13, por exemplo, Jesus estaria subordinado aos conselhos de Paula Lavigne, estando a imagem desta relacionada à de "um deus todo-poderoso").

Também faz parte da estrutura das NFs, em retrato do que ocorre em notícias, a presença de um rótulo, antecipando o texto, que se refere ao local em que o fato noticiado teria ocorrido. Neste caso, seria em "Odara", outro mecanismo-k que nos orienta para um contexto de paz e tranquilidade, em resgate da famosa música de Caetano. Para o mundo ficar odara, pra ficar tudo joia rara, seria preciso que todos obedecessem a Lavigne, publicando apenas o que ela autorizasse; um lugar que, portanto, contrasta com a violência com que ela age - esta é uma leitura autorizada (para ficar no mesmo campo semântico) a partir das pistas contextuais do autor das NFs. No decorrer do texto, há não só a referência ao personagem “Leãozinho", em retomada do título, mas também à "Geni", de uma música de Chico Buarque. Os dois estariam "reivindicando seus direitos" por terem sido citados em canções de seus respectivos compositores. A aproximação não é arbitrária: também Chico Buarque ${ }^{6}$ posiciona-se contra as biografias não autorizadas, em conformidade com a representante do Procure Saber. Há uma analogia construída tacitamente entre o absurdo de personagens famosos ("Leãozinho" e "Geni”) posicionarem-se contra a menção de seus nomes nas canções que os tornaram famosos e o absurdo que seria os respectivos compositores (Caetano e Chico) se oporem às biografias publicadas sem autorização. Há aproximação entre criadores e criaturas por suas posturas risíveis.

O mecanismo-k ainda opera no final da NF, ao ser apresentado o nome do cantor Lobão e dos verbo/expressão verbal de elocução "fez uma sugestão" e "tuitou". Esse novo tópico é introduzido na cadeia referencial e ativa uma memória acerca das declarações sempre polêmicas que o cantor faz em sua conta do Twitter. Na maior parte dos casos, estão longe de ser "sugestões", mas antes fortes críticas aos mais variados tipos de figura pública. Essa pista contextual é decisiva para que o leitor da NF conclua que a sugestão de solução do problema ser a troca de Geni por Lavigne é uma alfinetada ao modo como o cantor se posiciona, ou seja, de maneira agressiva e violenta, para não dizer estapafúrdia, como a de sugerir o “apedrejamento de Lavigne” como solução do problema. Por

\footnotetext{
${ }^{5}$ Não cabe aqui problematizar as concepções de verdade ou realidade, mas compartilho da ideia que uma fotografia é uma construção, revela um olhar de alguém, com suas subjetividades, para alguém, cujas subjetividades são reconstruídas por um enquadre. Além disso, já é de amplo conhecimento o poder de uma legenda associada a uma imagem. Portanto, "verdadeira" aqui se refere ao fato de ter sido veiculada em uma notícia (não fictícia).

${ }^{6}$ Em "Estudante da Puc-Rio é hospitalizada após discordar de artigo de Chico Buarque”, uma notícia fictícia que faz parte do corpus de exploração, ironiza-se o fato de ser tão difícil para muitas pessoas sequer imaginar que pudesse discordar de Chico Buarque, justamente por este ter sido reconhecidamente contra qualquer forma de censura.
} 
outro lado, isso também revela a posição do autor da NF, que reforça a imagem de Lavigne como a de vilã de toda a história, bastando ser "eliminada" para que a polêmica das biografias se resolva.

Também na NF(2), “Astros da MPB organizam Marcha da Família com Deus pela Privacidade” (17/10/13), é possível verificar o funcionamento de mecanismos-k decorrentes da organização estrutural desse gênero:

(2) Astros da MPB organizam Marcha da Família com Deus pela Privacidade 17/10/2013 16:17 | Categoria: Cultura

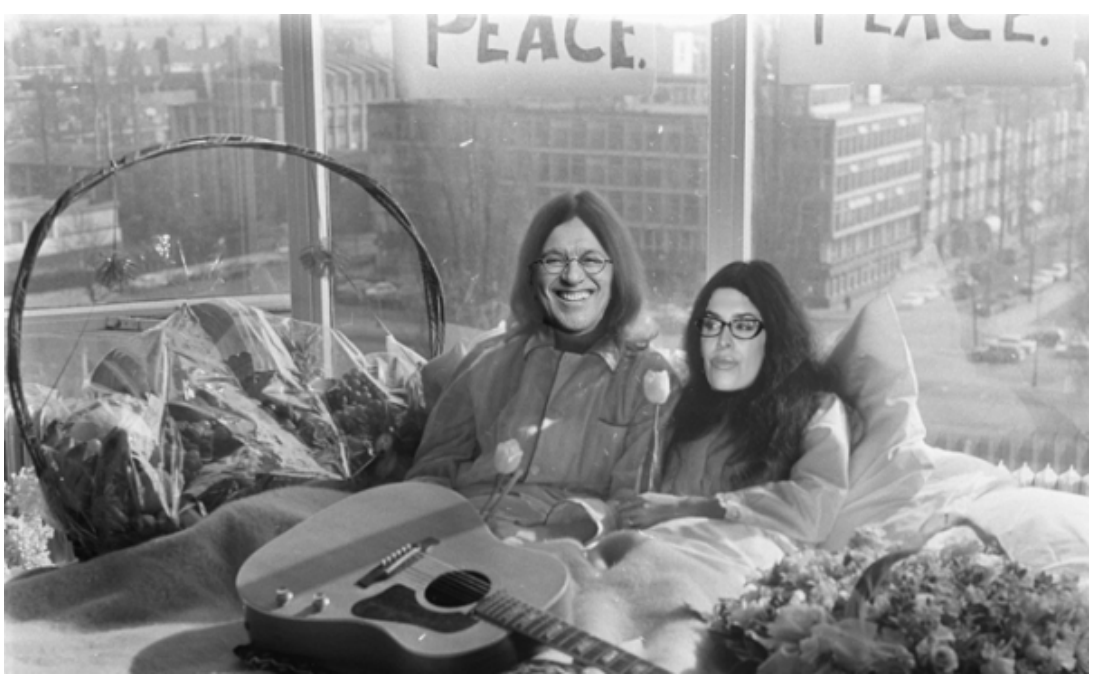

Paula Lavigne negou veementemente que seja a Yoko Ono da MPB

CINELÂNDIA - Para marcar posição contra as Reformas de Base lideradas por biógrafos incendiários e editores comunistas, astros da MPB convocam simpatizantes para a Marcha da Família com Deus pela Privacidade. "A privacidade da família da MPB não pode ser invadida por encalhadas como a Monica Bergamo e lésbicas como aquela moça do Saia Justa", ponderou Paula Lavigne, atrás de um discreto véu.

Caetano, Chico, Djavan, Gil e Roberto Carlos irão para as ruas cercados por uma área VIP móvel. "Dessa forma, ninguém invadirá a privacidade deles durante os protestos", explicou Lavigne, em coletiva na qual manteve-se a três metros de distância dos repórteres.

No final da tarde, correram boatos de que a NSA estava monitorando as ações da líder Paula Lavigne. Revoltada, a presidenta do Procure Saber disse que não concedeu autorização prévia para ser espionada.

Esforçando-se para se manter no páreo (em qualquer páreo), o candidato José Serra invocou a condição de ex-presidente da UNE para divulgar uma nota: "A passeata contra a guitarra elétrica é um retrocesso", disse. Informado por assessores de que a questão era outra, reagiu: "Ué, mudou?"

Perseguido pela MPB, o biografo Paulo Cesar de Araújo exilou-se em Marechal Hermes.

No agrupamento retórico foto-legenda, novamente identifica-se uma fotografia "real", que se refere, por conhecimento compartilhado, ao casal John Lennon e Yoko Ono, mas agora manipulada com a sobreposição dos rostos de Caetano Veloso e Paula 
Lavigne. Mais uma vez, em uma cadeia referencial que extrapola os limites do texto verbal, há retomada da aura de PazéAmor, instaurada na NF(1) por meio do mecanismo-k "Odara", o que é reforçado com o termo "peace" da imagem original. Na legenda, mais uma vez, há outra pista contextual, inclusive para quem não tivesse recuperado a informação sobre o casal retratado originalmente na fotografia: "Paula Lavigne negou veementemente que seja a Yoko Ono da MPB". É preciso mobilizar o conhecimento armazenado na memória de longo prazo de que Yoko Ono, por muito tempo, foi considerada a causadora do fim dos Beatles, uma vez que John Lennon teria abandonado a carreira na banda pelo amor à esposa artista plástica, cuja personalidade causava influência no cantor. Além disso, as escolhas lexicais como "negou veementemente" reforçam a construção de uma imagem enérgica e categórica de Lavigne.

No primeiro parágrafo da NF (2), há outro mecanismo-k ("Cinelândia”), que remonta à região do entorno da Praça Floriano, no cento do Rio de Janeiro, não só um reduto de bares, teatros e restaurantes, mas também palco de manifestações políticas importantes. A mobilização dessa informação é importante para a coesão temática, o que faz de "Cinelândia", além de mecanismok, um elemento coesivo, categorizando um dado fato construído dentro do campo semântico das manifestações. Mas uma manifestação que será ridicularizada pelas escolhas lexicais ("Astros da MPB”), pelas nominalizações ("Reformas de Base lideradas por biógrafos incendiários e editores comunistas", "Marcha da Família com Deus pela Privacidade") e pela escolha do verbo de elocução associado à, novamente, Paula Lavigne (“ponderou, atrás de um discreto véu”).

Em relação a este último, há uma ironia decorrente da contradição de associar o ato de ponderar - que não seria um costume da empresária - a declarações como esta que foi criada: "A privacidade da família da MPB não pode ser invadida por encalhadas como a Mônica Bergamo e lésbicas como aquela moça do Saia Justa”. Trata-se de uma declaração inventada, fictícia, entretanto respaldada por declarações reais, ou seja, a menção à colunista da Folha, Mônica Bergamo, e a alusão à jornalista que integra o programa Saia Justa, Barbara Gancia, bem como o modo como são referidas ("encalhada" e "lésbica do Saia Justa") apontam para notícias "reais". Foi tópico de algumas notícias, por exemplo, o fato de Lavigne ter feito as seguintes declarações:

(3) “@monicabergamo Monica deixa de ser chata e recalcada. Eu nem vi de quer era o perfil! Vc não tem mais o que fazer não! Mulher encalhada é foda!!!” (em sua conta no Twitter);

(4) “- Barbara, você é gay assumida, né?

- sou.

- qual o nome de sua namorada?

- Marcela.

- Ela não vai se sentir bem vendo eu perguntar isso, é disso que estou falando, você não está entendendo na teoria e agora viu na prática como é ruim ter a privacidade invadida!" (em diálogo durante o programa Saia Justa, do canal GNT).

No segundo parágrafo de NF(2), o objeto de discurso instaurado por "astros da MPB" é reconstruído por expressões como "cercados por uma área vip móvel", aproximando a imagem dos cantores que fazem parte do Procure Saber da figura do papa, que necessita de proteção diante da multidão de fiéis. Outra referência às exigências do percurso do papa é a informação de que Lavigne "mantevese a três metros de distância dos repórteres”. Associada a Deus e ao papa, além de caracterizada como líder que pode ser espionada pela extrema importância (terceiro parágrafo da NF(2)), há uma construção discursiva ao longo das NFs que é, em boa medida, baseada na recuperação do conhecimento acerca das notícias "reais", o que só é possível pelos mecanismos-k, operando de maneira sutil, uma vez que o propósito é humorístico. Dar pistas contextuais mais explícitas não seria proveitoso para os propósitos comunicativos das NFs.

De maneira semelhante ao que ocorre em relação ao cantor Lobão, na NF (1), outra pessoa pública, aparentemente destoante dos personagens principais, é inserida em NF (2): “José Serra” é mencionado ao lado de expressões como “ex-presidente da UNE” e de uma declaração aparentemente descabida: “A passeata contra a guitarra elétrica é um retrocesso”. Essas são pistas contextuais que 
aludem à biografia do político que, de fato, foi presidente da UNE, na ocasião da passeata contra a guitarra elétrica (encabeçada por músicos como Elis Regina, Geraldo Vandré, Edu Lobo etc.), que era um símbolo da interferência estrangeira na MPB. Assim como ocorre com a inserção da "voz" de Lobão, também há alfinetada a Serra, que aparece como cego diante dos fatos atuais e muito preso ao passado (outro posicionamento do autor). Por outro lado, na réplica “Ué, mudou?", questiona-se se, de fato, houve mudança de lá para cá, aproximando a passeata da guitarra elétrica ("real") - que foi considerada tradicionalista, a qual se opunha Caetano Veloso, por exemplo - da "Marcha da Família com Deus pela Privacidade" (fictícia). Assim, o autor da NF (2) revela que, por extensão, a polêmica das biografias é também um retrocesso, uma contradição para cantores que foram tão vanguardistas no passado.

Nas demais NFs do corpus, os mecanismos-k desempenham papel parecido ao que foi observado nas anteriores:

(5) Pelé desautoriza autobiografia escrita por Edson

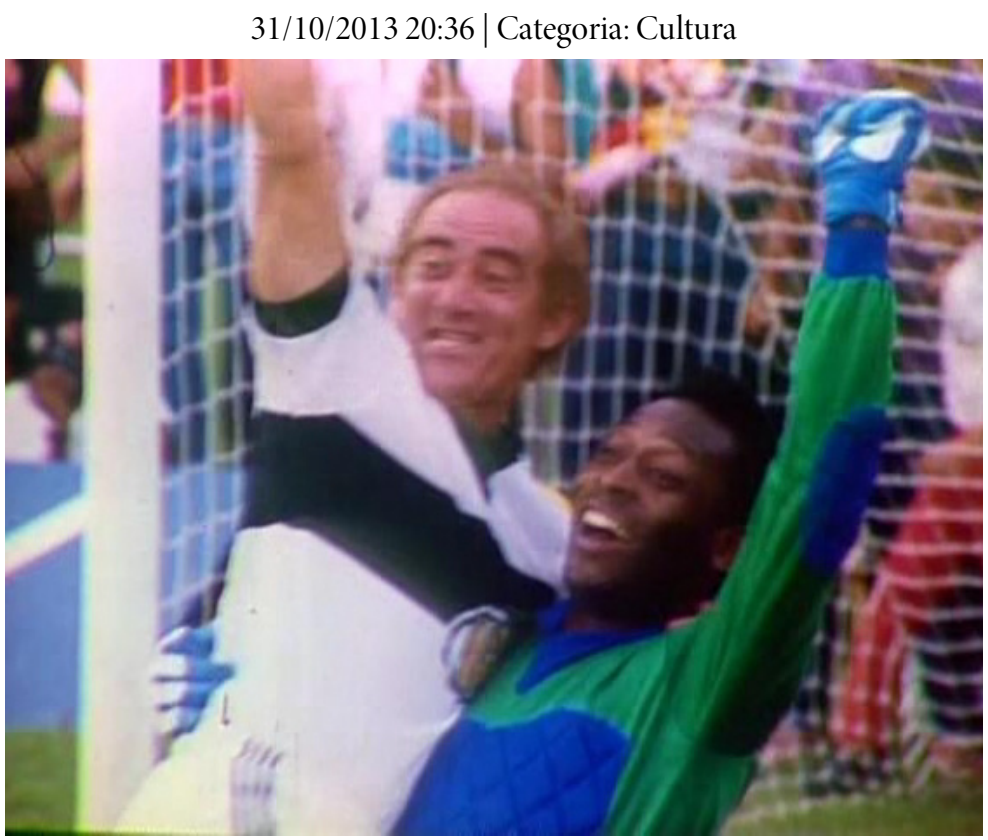

"Há detalhes que não quero revelar, entende?", confessou Pelé

TRÊS CORAÇÕES - "Eu não sei até que ponto a história do Pelé se confunde com a do Edson, entende?", justificou o jogador, antes de desautorizar que sua história fosse contada por sua pessoa física. Amparado na Constituição, no direito à privacidade, nos patrocinadores e respeitando sempre os adversários, Pelé proibiu sua autobiografia escrita por Edson Arantes do Nascimento.

Pelé esclareceu que nunca cantou "ABC, $\mathrm{ABC}$, toda criança tem que ler e escrever", não participou de um filme ao lado de Silvester Stallone e tampouco namorou a Xuxa: "Isso foi coisa do Edson, entende?"

Inspirados nos passos do craque, Arthur Antunes Coimbra censurou a autobiografia de Zico e a atriz Sônia Maria Vieira Gonçalves proibiu os 74 volumes da enciclopédia vivida de Susana Vieira. 
(6) Roberto Carlos manda Justiça recolher colunas de Caetano Veloso 07/11/2013 15:07 | Categoria: Cultura

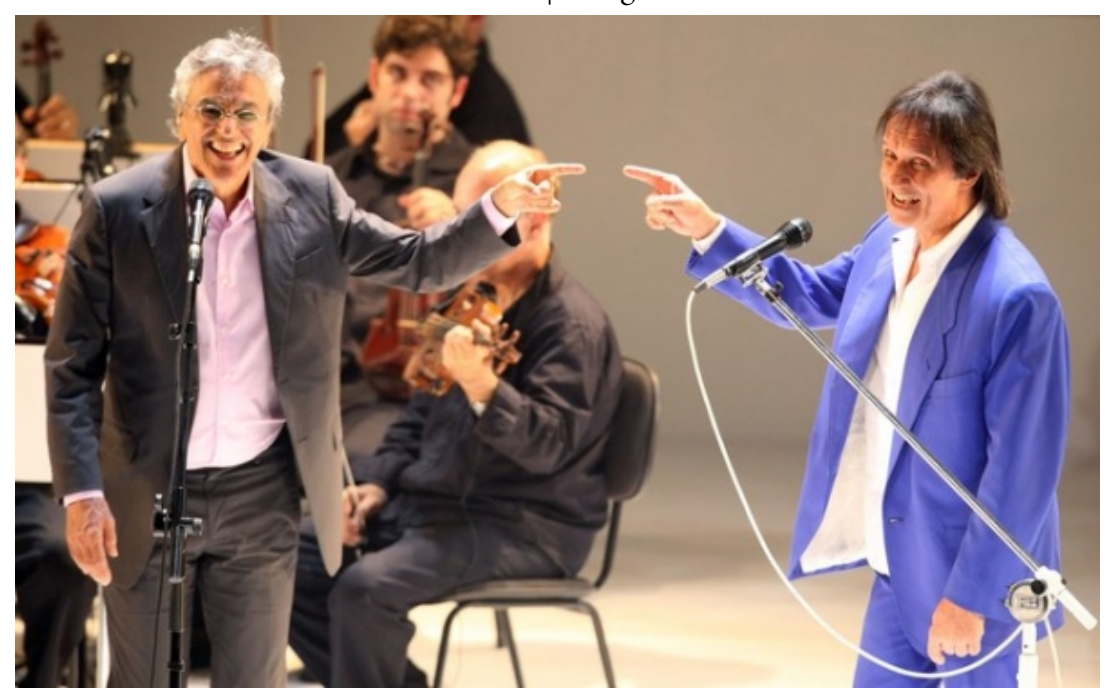

Caetano devolveu a versão Debaixo do botox de suas bochechas para Roberto

ALÉM DO HORIZONTE - Chateado com a maneira irônica com que foi retratado por Caetano Veloso no jornal O Globo, Roberto Carlos pediu para sua turma de advogados entrar com um pedido na Justiça para recolher todas as colunas já publicadas pelo artista. "São tantas decepções, bicho", desabafou o Rei.

De acordo com o processo, todas as edições de domingo de $O$ Globo impressas em 2013 devem ser recolhidas. Aposentados que guardam jornais em casa, passarinhos com gaiolas forradas e pintores que usam as páginas para proteger o chão deverão comparecer às delegacias de seus bairros com os jornais em mãos. Quem for flagrado com uma edição dominical de $O$ Globo em casa deverá pagar uma multa para o Ecad.

Vestida de marrom, Paula Lavigne voltou ao Saia Justa para revelar o nome da namoradinha de Roberto Carlos.

$\mathrm{Na}$ NF(5), Pelé desautorizaria autobiografia de Edson (do Nascimento), uma ironia semelhante a que ocorre entre os personagens das músicas dos compositores em NF (1); na em NF (6), a indicação do local em que o fato teria ocorrido também está no campo semântico da tranquilidade, já que "Além do horizonte" é uma alusão à música de Roberto Carlos que trata de "um lugar bonito e tranquilo". Nele, não haveria "Caetanos" escrevendo em jornais dominicais, modificando sua posição - antes desfavorável - às biografias sem autorização do biografado: "São tantas decepções, bicho", em alusão a "São tantas emoções" (enunciado recorrente de Roberto Carlos), seria a reação a essa mudança. Isso porque RC vetou sua biografia e também é contra a publicação de biografias sem o crivo do biografado. Há um diálogo, portanto, entre as posturas de Roberto Carlos e Paula Lavigne, no que tange ao modo contundente com que defendem suas posições, reforçado ironicamente pelos rótulos "Além do horizonte" e "Odara”. Também é feita referência à Lavigne e suas declarações pela expressão "vestida de marrom”, outro mecanismo-k que alude à imprensa marrom, uma expressão pejorativa que se refere aos veículos sensacionalistas e antiéticos, e relembra o que já foi aludido na própria produção das NFs sobre sua postura no programa Saia Justa. 


\section{CONSIDERAÇÕES FINAIS}

Como vimos, ler um texto é reler muitos outros em nossa memória. Muito antes da produção e da leitura de um texto, ativamos nossos modelos mentais, instaurados e constantemente reformulados por nossas experiências, acerca de como agir socialmente por meio da linguagem. Esse processo diz respeito, dentre outros fatores, aos modelos de contextos que construímos ao longo da vida. São eles que são ativados constantemente durante a interação para que haja compreensão, uma vez que é preciso compartilhamento de informações entre os interlocutores. Ao longo deste estudo, procurei ajustar o olhar no que diz respeito à maneira como os modelos de contexto são ativados em notícias fictícias, por meio do mecanismo-k.

Tendo em vista a hipótese de que, em notícias fictícias, assim como nas charges, os mecanismos-k funcionam sutilmente, uma vez que as pistas contextuais precisam ao mesmo tempo sinalizar o contexto para que haja compreensão e implicitar o suficiente para que haja humor, foi possível verificar o quanto esse mecanismo é imprescindível para a cadeia referencial de notícias, mesmo as fictícias, de um mesmo momento discursivo. Nesses casos, deve haver pistas não só quanto ao contexto interno das NFs como também ao externo, referente às notícias "reais". Ademais, ficou claro que o modo como operam os mecanismos-k são fortemente distintos, quanto ao grau de explicitude, em NFs e notícias, o que também sinaliza para a importância de se observar este traço composicional dos gêneros para o estudo de sua função social. Por fim, depois desse primeiro olhar sobre as NFs e sobre o mecanismo-k, emergem algumas questões que pretendo retomar futuramente, mas que, desde já, podem estimular outros estudos: em que medida a intertextualidade se relaciona com o mecanismo-k? Seria este um sinalizador de intertextos? Como caracterizar as NFs: é um novo gênero? Quais seriam as diferenças entre as NFs do i-Piauí-Herald e as de outros suportes, como o "Diario Pernambucano - falsiê, mas sem farsas" e o "Sensacionalista - um jornal isento de verdade"? Como se comportam os leitores diante das NFs desses sites: leem os textos como acontecimentos "reais", ficção/piadas, crítica? Por quê? Espero que outras perguntas se juntem a essas e possam nortear novos empreendimentos acerca das notícias fictícias e/ou do mecanismo-k.

\section{REFERENCIAS}

ASTROS da MPB organizam Marcha da Família com Deus pela Provacidade. The í-Piauí-Herald, 17 out. 2013. Disponível em:<http://revistapiaui.estadao.com.br/blogs/herald/cultura/astros-da-mpb-organizam-marcha-da-familia-com-deus-pelaprivacidade>. Acesso em: 10 jul. 2014.

BAZERMAN, C. Atos de fala, gêneros textuais e sistemas de atividades: como os textos organizam atividades e pessoas. 3. ed. In: BAZERMAN, C. Gêneros textuais, tipificação e interação. São Paulo: Cortez, 2009. p. 19-46.

CAVAlCANTE, M. M.; PINHEIRO, C. L.; LINS, M. P. P.; LIMA, G. Dimensões textuais nas perspectivas sociocognitiva e interacional. In: BENTES, A. C.; LEITE, Q. M. (Org.). Linguística de texto e análise da conversação - panorama de pesquisas no Brasil. São Paulo: Cortez, 2010. p. 225-261.

KOCH, I. G. V. Introdução à linguística textual: trajetória e grandes temas. 2.ed. São Paulo: Martins Fontes, 2009.

KOCH, I. G. V.; CUNHA-LIMA, M. L. Do cognitivismo ao sociocognitivismo. In: MUSSALIM, F.; BENTES, A. C. Introdução à linguística - fundamentos epistemológicos. v.3. 5. ed. São Paulo: Cortez, 2011. p. 251-300.

LEÃOZINHO exige autorização para ser citado por Caetano Veloso. The í-Piauí-Herald, 11 out. 2013. Disponível em: $<$ http://revistapiaui.estadao.com.br/blogs/herald/cultura/leaozinho-exige-autorizacao-para-ser-citado-por-caetano-veloso>. Acesso em: 10 jul. 2014.

MARCUSCHI, L. A. A construção do mobiliário do mundo e da mente: linguagem, cultura e categorização. In: MARCUSCHI, L.A. Cognição, linguagem e práticas interacionais. Rio de Janeiro: Lucerna, 2007. p. 124-145. Série Dispersos. 
MARCUSCHI, L. A. Produção Textual, análise de gêneros e compreensão. São Paulo: Parábola, 2008.

MILLER, C. R. Gênero como ação social. In: MILLER, C. R. Estudos sobre gênero textual, agência e tecnologia. Recife: Editora Universitária da Universidade Federal de Pernambuco, 2009. p. 19-45.

MOIRAND, S. L'impossible clôure des corpus médiatiques. Tranel, 40, 2004.

MOIRAND, S. L'impossible clôure des corpus médiatiques - La mise au jour des observables entre catégorisation et contextualisation. Tranel (Travaux neuchtelois de linguistique), Suiça, v.40, p.71-92, 2004. Disponível em:<https://doc.rero.ch/record/12852/files/tranel_n_40_2004.pdf>. Acesso em: 15 ago. 2014.

MONDADA, L.; DUBOIS, D. Construção dos objetos de discurso e categorização: uma abordagem dos processos de referenciação. In: CAVALCANTI, M. M.; RODRIGUES, B. B.; CIULlA, A. (Org.). Referenciação. São Paulo: Contexto, 2003. p. 17-52.

PELÉ desautoriza autobiografia escrita por Edson. The i-Piauí-Herald, 31 out. 2013. Disponível em:<http://revistapiaui.estadao.com.br/blogs/herald/cultura/pele-desautoriza-autobiografia-escrita-por-edson>. Acesso em: 10 jul. 2014.

ROBERTO Carlos manda Justiça recolher colunas de Caetano Veloso. The i-Piauí Herald, 7 nov. 2013. Disponível em: $<$ http://revistapiaui.estadao.com.br/blogs/herald/cultura/roberto-carlos-manda-justica-recolher-colunas-de-caetano-veloso $>$. Acesso em: 10 jul. 2014.

VAN DIJK, T. A. Discurso e contexto - uma abordagem sociocognitiva. Trad. Rodolfo Ilari. São Paulo: Contexto, 2012. 